\title{
The Art/Technology Interface: Innovation and Identity in Information-Age Ireland
}

\author{
Mads Haahr \\ Department of Computer Science \\ University of Dublin, Trinity College
}

\begin{abstract}
Ireland was subject to a considerable transformation towards the end of the 19th century and again at the end of the 20th century with the Celtic Tiger boom. The latter can be seen as a particularly fast-tracked phase of a longer transformation of Irish society from an agricultural/industrial society into an informational society. This paper traces current trends in this transformative process and proposes that the interface of art and technology will come to play an important role for two key tasks for the informational society: the fostering of innovation and the construction of identity.
\end{abstract}

\section{The Art/Technology Interface}

In order to discuss the interface between art and technology in a meaningful manner, we need first to define the terms 'art' and 'technology.' Both terms have a considerable number of meanings that have evolved over the last centuries. A comprehensive etymological analysis is beyond the scope of this paper, and the reader is referred to an account by Mick Wilson (2001). For the purposes of this paper, we will consider 'art' the application of creativity and 'artworks' (whether physical objects, performances or digital creations) the results of such applied creativity. The best artworks provoke us, offer us insight and change the way we think about things. They challenge our assumptions about the world, in particular those assumptions of which we were not previously aware. The term 'technology' will be used to refer to the body of tools available to humanity at any given point in time. Our technology has been assembled over millennia and is in continual development. The term 'technological development' refers to the expansion of this body of tools through research and innovation. As new technologies (sets of tools) are added, old ones receive less prominent roles in, or are completely removed from, the collection, or become so subsumed as not to be experienced as 'technology.' Papyrus as a technology for transferring knowledge has been surpassed by paper, which may in time be surpassed by digital media. The typewriter, as a technology for making inscriptions on paper, has almost been completely surpassed by the word processor. The pen is so commonplace it is no longer considered technology in most cases.

Art and technology both constitute domains of considerable importance to human endeavour. Although we now draw very distinct lines between the two, the radical separation between them can be traced back to the 19th century and is therefore a relatively recent historical phenomenon (Wilson 2001). One may wonder as to the value in connecting these two, now clearly distinct, domains and as to the wisdom in jeopardising what may seem like a perfectly sensible dichotomy. However, such blending is quite popular in the informational society, and there are many other examples of domains being connected that until recently have been considered separate. For example, bioinformatics blends computer science and biology, elearning blends computer science and education and neuroesthetics blends 
neurobiology and aesthetics. In many cases, the combination of different fields allows a subject to be approached from different angles simultaneously, and the combination of alternative perspectives can lead to a deeper understanding of the subject and its processes. This paper first discusses the current transformation of Irish society (a longer, ongoing project) and then presents two processes within this transformation that the art/technology interface is likely to affect greatly: fostering innovation and constructing identity.

\section{Ireland's Current Transformation}

Irish society has undergone two transformations in recent history: one in the 1890s, with the creation of nationalist Ireland, and another in the 1990s with the creation of neo-liberal Ireland, also known as the Celtic Tiger (Kirby 2002b). The reinvention of Ireland during the Celtic Tiger years can be seen as a particularly fast-tracked phase of a longer process of transformation towards what Manuel Castells has called the network society (2000a). The network society is defined by the pervasive presence of the network - as opposed to the hierarchy — as an organisational principle. The model describes society as a set of nodes (e.g., centres of political or financial power), which interact to form flows that can be for example political, financial or informational in nature. As opposed to the hierarchy, the network is a highly flexible structure that reacts quickly to changes. The network society comes with its own brand of capitalism, informational capitalism, which relies on 'innovation-induced productivity and globalization-oriented competitiveness to generate wealth' (Castells 2000b: 369). Hence, in the network society, innovation is a prime currency.

Analyses of Irish culture, society and economy support the interpretation of the Celtic Tiger years as a phase of Ireland's transformation to a network society. For example, Paedar Kirby et al. observe a shift in social values associated with the Celtic Tiger transformation as follows,

[T] he emergence of informational capitalism and Ireland's semi-peripheral integration into it bring to the fore a cultural discourse prioritising individualism, entrepreneurship, mobility, flexibility, innovation, competitiveness both as personal attributes to be cultivated by the individual [...] and as dominant social values. These displace earlier discourses prioritising national development, national identity, family, self-sacrifice, selfsufficiency and nationalism. (2002a: 13)

While the shift in focus described by the authors is certainly not limited to Ireland, the Irish transformation has been particularly dramatic, mainly due to the speed and force (both attributable to the injection of considerable foreign investment during the 1990s) with which it took place. Although this transformation has been widely welcomed by the Irish, it has also been criticised. Elsewhere, Kirby observes that while the bases for Ireland's most recent reinvention have 'helped deliver high growth rates, high employment growth and large average increases in income,' they have also 'resulted in greater inequality in the distribution of this growth,' have 'accompanied a weakening in the state's welfare effort' and 'led to a growing concentration of power in the hands of economic and political elites' (2002b: 32).

It is worth noting that the shift in focus described by Kirby et al. includes the replacement of the Irish national identity with nothing in particular. Elsewhere, Kirby 
describes neo-liberal Ireland as 'offer[ing] a more solid economic base' and a 'looser sense of identity' (2002b: 34) than nationalist Ireland. Castells devotes an entire volume to the topic of identity in the network society and also identifies the dissolution of shared identities as one of its characteristics (1997: 355). Thomas Hylland Eriksen, writing on the topic of time in the information age, compares the construction of identity to a box of Lego bricks, which in the industrial society came with a set of instructions that encouraged you to build one of a predefined set of identities (e.g., carpenter or store clerk), but which in the informational society comes without instructions and furthermore requires you to modify your construction on a daily basis (2001: 124).

The transformation of nationalist Ireland to neo-liberal Ireland raises a host of issues of which this discussion has highlighted two: innovation and identity. Innovation is the main enabler of production in the network society, and if Ireland wishes to reinvent itself as a knowledge-producing economy, innovation should be high on the agenda. At the same time, the dissolution of shared identities poses considerable problems for individuals born in a society recently based on solidity, roots and belonging. It is therefore hardly surprising that Irish society is becoming increasingly preoccupied with innovation and identity, and that both terms have been promoted to buzzword status. The following sections discuss how the art/technology interface can be used to (1) foster a high level of innovation, and (2) construct identity by increasing awareness of shared pasts.

\section{Creating Innovation}

The interface between art and technology is very much about connecting things that have not before been connected. By combining old things, new things are created. One purpose of the art/technology interface is therefore related to innovation - the domains are connected with the deliberate intention of producing new ideas. In general, it is hardly surprising that a society based on informational capitalism should combine domains in this fashion. Where innovation is the holy grail, the mixing of disciplines is gospel, and the resulting ideas are eagerly sampled. 'Mix, stir and sample' seems to be the mantra of the informational society. The particular blend of art and technology has received considerable attention as well as funding over the last couple of decades, and institutions in Europe (e.g., Ars Electronica) as well as the United States (e.g., Xerox PARC) have combined people from both disciplines, for example through artist-in-residence programmes (Harris 1999; Candy 2002).

Experience with innovation-focused programmes that feature collaboration between artists and scientists for research purposes have identified a number of possible modes of interaction between the two camps. Stephen Wilson (1999: 187), an artist working with emerging technologies who participated in the Xerox PARC artist-in-residence programme, lists three such modes of interaction between artists and technology:

1. Artists can be consumers of technology, i.e., users of new technological tools for the creation of artworks, for example images, sound and video.

2. Artists can be commentators of technology, i.e., they can comment critically on technological developments through their art.

3. Artists can be researchers, i.e., participating actively in the creation of new technologies. 
The three modes of interaction are of course not mutually exclusive, and combinations are possible. Although the first two modes are significant, Stephen Wilson stresses the importance of the third, saying that 'artists must work at the heart of the research process and not just as consumers of technological gadgets' (1999: 187). To facilitate innovation, artists must engage in the process of technological research and development; it is not enough merely to be a user or commentator. When such programmes work, the experiences are positive. For example, Craig Harris describes the results of pairing artists with researchers in Xerox PARC as 'both interesting art and new scientific innovations' (1999: xii).

What is the Irish tradition for fostering innovation? In terms of literary innovation, the Irish influence on the 20th century is dramatically (and wonderfully) out of proportion to the size of the country. In terms of technological innovation, Ireland's role in the last century has been somewhat less glamorous. During the Celtic Tiger boom, many software companies set up production in Ireland, and Irish politicians rarely missed an opportunity to stress that the country was one of the biggest exporters of software in the world, second only to the United States. Although there are indigenous Irish software companies (e.g., IONA Technologies) who do their research and development in the country, the majority of jobs related to the Irish software exports have little to do with innovation; the majority of tasks performed in Ireland are related to telesales, customer support, software localisation and the writing of software developed abroad onto physical storage media.

There have been a number of attempts to foster innovation by interfacing of art with technology in Ireland. Many Irish universities have multimedia programmes that aim to combine art and technology in two ways. One intention is to integrate people with complementary skills in the same learning environment. This is a type of interpersonal art/technology interface, which has the purpose of facilitating and teaching collaboration between people with very different backgrounds and skill sets. Another intention is to develop the 'other side' in students whose expertise lies predominantly in one of the areas. This is a type of intrapersonal art/technology interface, which has the purpose of producing multi-skilled individuals. In terms of Wilson's three modes of interaction, multimedia programmes with this agenda attempt to facilitate the third mode of interaction (research) through the training in the first (consumption) and second (critique).

The multimedia degrees are examples of government-sponsored initiatives to support research on the art/technology boundary. Due to their nature as taught courses with little scope for actual technological development, such degrees cannot directly address Wilson's third mode of interaction, but the courses do contribute to this type of interaction in an indirect fashion, through the training of individuals suitable for multidisciplinary research. Government support for developing the more important third mode of interaction is still lacking. Organisations such as the Irish Research Council for Science, Engineering and Technology (IRCSET) and Enterprise Ireland are useful for fostering the basic and industry-focused research initiatives required to create innovation based on technology. The Irish Research Council for the Humanities and Social Sciences (IRCHSS) sponsors research in the arts and humanities. However, it is far from trivial to find funding for inherently multidisciplinary projects through existing funding bodies. (Imagine a technology research proposal listing as staff two postgraduate students, one computer scientist and one sculptor.) An important exception is the June 2000 opening of Media Lab 
Europe (MLE), the European research partner of the MIT Media Lab, in Dublin. MLE constitutes a government-supported industry initiative to foster technological innovation through art/technology research.

Another problem related to government-sponsored research projects on the art/technology boundary is that principal investigators need to manage employees from different disciplines. The skill sets required to manage a dramatically multidisciplinary team are different from those required to manage a more homogenous team. Although this may be particularly true for academia, a similar case could be made for industrial research and development environments. Principal investigators and managers may of course also ask the very sensible questions: How can artists contribute to research? Is there a case for collaboration? Tor Nørretranders offers an interesting discussion on this topic, arguing that artists (and others) display in their work an enormous tacit knowledge, and that this knowledge can be tapped through collaboration with scientists. In fact, such implicit knowledge often precedes the explicit, formalised knowledge, and science can be regarded as 'an articulation and explication of knowledge that is already being applied' (1998: 307). Nørretranders uses as his example collaboration between film editors and vision researchers. Where the latter are interested in understanding how human vision works, the former understand what works for humans visually. Implicit knowledge is often embodied in 'rules of the trade' that may be more or less well defined. For example, two people edited into a news report must be facing each other or they will appear not to communicate. Such implicit knowledge bears witness about our brains' expectations about the visual input they receive, and therefore about the way in which our brains process visual information. Whether embodied in rules or not, implicit knowledge can be made explicit through interdisciplinary collaboration.

Nørretranders concludes that 'scientists studying vision can learn a lot from film editors' (1998: 306).

To summarise, using the art/technology interface for the purpose of innovation is an idea that has been applied successfully elsewhere and is currently being deployed in Ireland. The combination of the two domains has been shown to have a good potential for innovation, but there are impediments to this potential being realised in an Irish context. While existing postgraduate education programmes train individuals for research on the art/technology border, the mode of interaction between artist and technology most conducive to innovation is still neglected. This is true in public as well as privately sponsored research. With the exception of MLE, the public research funding structures are not tailored for such multifaceted research, and while some technology companies sponsor MLE and thereby get joint ownership of ideas developed in the research lab, very few employ artists in their own research and development.

\section{Building Identity}

As discussed above, the construction of identity in the network society is governed by different rules than in the hierarchical society. The network society's looser sense of identity, the lack of guidelines as to its construction and the requirement for continual reconstruction open up a space of possibilities that is both exciting and daunting. For the individual, constructing and reconstructing one's identity on a daily basis (Eriksen 2001: 124) can be exhausting as well as intimidating. 'Invent yourself,' thunders informational capitalism and, with little regard for human need for rest, forces us 
constantly to think of new answers to the question: 'What will I be today?' The resulting process of repeatedly producing new answers to this question defines identity in the network society. In Castells' words: 'In a world of global flows of wealth, power, and images, the search for identity, collective or individual, ascribed or constructed, becomes the fundamental source of social meaning' (2000a: 3).

Another potential consequence of the overwhelming range of possible identities is that '[i]dentities become more specific and increasingly difficult to share' (Castells 2000a: 3). Kirby et al. agree, stressing that,

[w] hile inevitably there is pluralism in all cultures, no society could exist without some common values, beliefs and meanings to hold it together. A concentration on the plurality of cultures can obscure these foundational elements of culture (2002a: 16$)$.

Castells distinguishes between 'dominant, global elites inhabiting the space of flows' and 'people resisting economic, cultural and political disfranchisement' (1997: 356). The former are described as identity-less ('citizens of the world'), while the latter as attracted to communal identity. For the latter group (supposedly the majority of the planet's population), Castells lists religion, nationality and locality as the three themes around which shared identities can be constructed (1997: 65). In an Irish context, the increasing popularity of the Irish language during the 1990s can be interpreted as an affirmation of local identities in response to economic globalisation but also as an initiative to draw upon the Irish 'linguistic and cultural past to situate people in the present' (Kirby 2002a: 14).

The following briefly presents and discusses three art/technology works that address identity based on Irish inheritance. Each work addresses one of Castells' three themes (religion, nationality and locality) around which shared identities can be constructed. The works also illustrate differences in terms of media (one is an installation, two are multimedia applications), purpose (one is a commercial product, the others student projects) and intention (one is evocative, another educational and the third designed specifically to foster a sense of identity).

Advanced Mediation (McElligott 2000) is an interactive confessional box designed and built by Lisa McElligott as part of her MA in multimedia at the University of Limerick. The installation incorporates a real confessional box in which the role of confessor is played by a computer program that interacts with the penitent through a voice interface. The computerised priest, situated behind the screen as a real priest would be, recognises key words and phrases spoken by the penitent, offers encouragement and criticism during the conversation and finally metes out appropriate penance. The work is highly evocative for several reasons. First, the confessional box used is authentic, lending an immediately convincing atmosphere to the installation. Second, the confessional situation is of course highly emotionally loaded for most Catholics. Third, perhaps somewhat surprisingly, the confessional scenario actually lends itself quite well to automation, allowing the work to be well executed within the confines of existing technology. For example, during a 'proper' confession, the confessor is of course hidden from the penitent, and the replacement of the human with the computer in McElligott's piece does therefore not alter the physical appearance of the situation. Also, the conversation between confessor and penitent lends itself well to algorithmic expression, simply due to its formal structure. These characteristics of the confessional scenario allow the technology to remain 
relatively hidden and thereby prevent it from immediately breaking the suspension of disbelief.

The award-winning Book of Kells CDROM (X Communications 2000) is a multimedia application that implements an interactive version of the Book of Kells. All 340 vellum folios are presented as high-quality image scans, and a user interface allows the viewer to peruse the book and examine individual pages in detail. In addition, the application contains background information in the form of a series of thematic, historical, religious and technical commentaries. As a commercial multimedia application, the Book of Kells CDROM has no physical components beyond its storage medium, and its main purpose is educational.

WeirdView (Nisi 2000; Nisi 2002) is a multimedia application designed and implemented by Jo Briggs and Valentina Nisi as part of their MSc degrees in multimedia from Trinity College Dublin. The piece centres around Weir View, a terrace of houses in Dublin, affectionately know as 'Weird View' to its inhabitants. The two authors collected a series of true stories from Weir View inhabitants through an interview process and supplemented the stories with video, photography and historical facts to form a series of narrative fragments. The fragments were hyperlinked to form an anecdotal story space, which can be navigated by the audience. For example, one fragment recounts that "Uncle Terry "taught" Mickey to swim. The boy was throw into the Liffey, attached to a rope.' In this text, the word 'Mickey' constitutes a hyperlink to another fragment, explaining how 'Mickey loved his motorbike so much he'd take it to bed with him.' Photographs accompany both narrative fragments. In this way, WeirdView attempts to capture a portion of the community folklore and re-present it to the community in the form of an interactive non-linear narrative. The intention is that increased awareness of a shared past will strengthen the feeling of belonging to the locality and the sense of community among the inhabitants of the Weir View terrace.

Works such as these draw upon Irish traditions in various manners. Through its parody of confession, Advanced Mediation brings forward the Irish Catholic tradition - more specifically the institutionalisation of sin and penance - for examination. This is a critical work that asks questions about the Irish religious identity. In comparison, the Book of Kells CDROM asks no questions, but is rather a new representation of a key piece of Irish cultural inheritance. While its subject matter is of course religious, it could be argued that the Book of Kells has been institutionalised to such an extent that its electronic representation relates to Irish national as well as religious identity. The WeirdView application is deliberately intended to foster increased awareness of a common background for a community sharing a particular geographical location; this work therefore addresses local identity.

\section{Conclusion}

This essay has mapped out the creation of innovation and the construction of identity as two areas for which the art/technology interface promises to hold considerable potential as transformative energies. The current transformation that the Irish society is undergoing was outlined, and the two areas were placed within this context. The author will be the first to acknowledge that the treatment given here is far from exhaustive, and many questions have been left open. First, the essay has treated innovation and identity as separate areas, whereas of course in reality there are 
interactions between the two. For example, innovation due to its importance as a prime currency for informational capitalism is being presented as an attractive trait that individuals are encouraged to acquire and integrate into their personal identity. The notion of interaction between the two streams also raises another issue. The artworks discussed in relation to the construction of identity are of course also relevant in the context of innovation, and a natural question would be to what extent the works discussed bear witness to a process like that described by Stephen Wilson. Were the artists in question users, critics or researchers of the technology? Answering this question properly requires a more thorough analysis of the artistic process than possible within the confines of this essay.

It could be argued that the two streams of transformative energy can be seen as working in opposite directions. While the highly conscious pursuit of innovation certainly encourages the development of values associated with informational capitalism, the ability of art on the art/technology boundary facilitates the construction of religious, national and local identity. Perhaps an interesting space for future ideas can found between these two seemingly opposite streams. Kirby et al. call for 'an argument for an innovative appropriation of culture as a means of developing a new critical political space within contemporary Irish society' (2002a: 4). Perhaps the art/technology interface can serve to (re)appropriate culture in an innovative manner, and the technologically savvy artist help bring about this appropriation.

This paper has traced the role of artists as participants in processes related to creating innovation and constructing identity. An alternative, although not conflicting, view is offered by Marshall McLuhan who places the technologically savvy artist as analyst or mediator, arguing that he or she has the insight required to shape the technologies and therefore holds a special role in relation to technology:

The effects of technology do not occur at the level of opinions or concepts, but alter sense ratios or patterns of perception steadily and without any resistance. The serious artist is the only person able to encounter technology with impunity, just because he is an expert aware of the changes in sense perception. (1964: 19)

McLuhan's 'serious artist' can retain awareness of the way in which technology affects us through a heightened sense of perception and acute awareness that everything we see and do moulds us, changes what we are and how we perceive things. The abyss gazes back; we become what we behold. While we cannot perceive without being affected, McLuhan's 'serious artist' remains aware of the effect and can therefore retain a greater degree of control. As many authors have observed, technologies in the information age are generally being developed and marketed with the intention of rapid profit and often with surprisingly little regard for the consequences. McLuhan's 'serious artist' is in a unique position to understand the effect of these technologies and to help shape them according to his/her beliefs. These beliefs may of course be related to capitalism (i.e., the artist's objective may be simply to earn money) but may also be based in a concern for the greater good of humanity. Perhaps the technologically savvy artist's most noble task is to identify and understand the transformative energies at work, to tell us how we are being affected by industry-driven technological developments, where we are headed and how fast we are going. 


\section{References}

Candy, Linda and Edmonds, Ernest. 2002. Explorations in Art and Technology. London: Springer-Verlag.

Castells, Manuel. 1997. The Power of Identity. Oxford: Blackwell Publishers.

Castells, Manuel. 2000a. The Rise of the Network Society. 2nd ed. Oxford: Blackwell Publishers.

Castells, Manuel. 2000b. The End of Milleniun. 2nd ed. Oxford: Blackwell Publishers.

Eriksen, Thomas Hylland. 2001. The Tyranny of the Moment. London: Pluto Press.

Harris, Craig. 'The Xerox Palo Alto Research Center Artist-in-Residence Program Landscape.' In Art and Innovation: The Xerox PARC Artist-in-Residence Program, edited by Craig Harris, 2-34. Cambridge, MA: MIT Press.

Kirby, Paedar and Luke Gibbons and Michael Cronin. 2002a. 'The Reinvention of Ireland: A Critical Perspective.' In Reinventing Ireland: Culture, Society, and the Global Economy, edited by Paedar Kirby, Luke Gibbons and Michael Cronin, 1-18. London: Pluto Press.

Kirby, Paedar. 2002b. 'Contested Pedigrees of the Celtic Tiger.' In Reinventing Ireland: Culture, Society, and the Global Economy, edited by Paedar Kirby, Luke Gibbons and Michael Cronin, 21-37. London: Pluto Press.

McElligott, Lisa. 2000. Advanced Mediation.

McLuhan, Marshall. 1964. Understanding Media. New York: McGraw-Hill.

Nisi, Valentina and Jo Briggs. 2000. WeirdView. http://www.weirview.com/

Nisi, Valentina and Mads Haahr. 2003. 'Interactive Multilinear Narratives and Community Real-Life Stories.' In Proceedings of Images of Life: Exploring the New Foundations of Visual Studies.

Nørretranders, Tor. 1998 (1991). The User Illusion: Cutting Consciousness Down to Size. Translated by Jonathan Sydenham. London: Penguin.

Wilson, Mick. 2001. 'How Should We Speak About Art and Technology?' Crossings: Electronic Journal of Art and Technology 1.1.

Wilson, Stephen. 1999. 'Reflections on PAIR.' In Art and Innovation: The Xerox PARC Artist-in-Residence Program, edited by Craig Harris, 186-208. Cambridge, MA: MIT Press.

X Communications. 2000. The Book of Kells CDROM. Dublin: Trinity College Library. 